государственного органа, функционал госслужащего, темп и интенсивность работы); организационно-технические (оснащенность рабочего места, уровень комфорта рабочей среды, техникотехнологическое обеспечение профессионально-служебной деятельности); профессионально-квалификационные (степень соответствия сотрудника по профессионально-квалификационным, моральным, психологическим качествам).

В зависимости от того, каким содержанием наполняются вышеизложенные «переменные», можно выделит различные типы конфликтов в государственноадминистративной сфере.

1) структурно-организационные конфликты (вызваны ошибками в построении структуры государственного органа или ее изменении; проблемами качестватехнического и технологического оснащения рабочих мест госслужащих; просчетами в распределении функциональных обязанностей);

2) функционально-организационные конфликты (обусловлены недостаточностью взаимодействия госоргана с внешней средой, недостатками организации взаимодействия госслужащих внутри организации; недостаточностью или искаженностью коммуникаций);

3) личностно-функциональные (неполное соответствие госслужащего замещаемой должности по профессиональным,моральным и иным качествам; плохой эмоциональный микроклимат в коллективе; субъективный подход руководителей);

4) ситуативно-управленческие (просчеты в принятии и исполнении политических и управленческих решений).

Представленный подход к типологии основан на понимании государственной службы как многомерного, динамично развивающегося социально-политического и правового института российской государственности. Его применение, как представляется, позволит выявить многообразные конфликтогенные факторы в государственно-административной сфере, в целях профилактики их развития.

$$
* * *
$$

1. Гимазова Ю.В., Знаменский Д.Ю., Омельченко Н.А., Харичкин И.К. Взаимодействие государства и социально ориентированных некоммерческих частных организаций. - Москва, 2015.

2. Магомедов К.О. Конфликт интересов в системе государственной гражданской службы: социологический аспект исследования проблемы // Государственная служба. - М., 2005. № 6. С. 32 37.

3. Попова О.В. Регулирование социальных конфликтов государственной гражданской служचбой. - М., 2006. $203 \mathrm{c}$.

4. Тимофеева Л.Н. Конфликты на государственной службе. - М., 2009. 175с.

\title{
Кулинченко А.В. \\ Марксизм-ленинизм об управлении обществом: идеалы и их революционное воплощение в России
}

Финансовый университет при Правительстве РФ (Россия, Москва)

doi:10.18411/spc-10-01-2018-07

idsp: 000001:spc-10-01-2018-07

Революция 1917 года в России была обусловлена действием многих причин и факторов, как внутренних, так и внешних. Одним из факторов, оказавших значительное влияние на октябрьский переворот и последующее развитие событий, была марксистская теория общественного развития, положениями которой во многом руководствовалась захватившая власть партия большевиков. Совершая пролетарскую революцию в крестьянской стране, большевики нередко были вынуждены отступать от 
её важнейших положений, сохраняя, тем не менее, основную задачу и цель разрушение старого и построение нового общества, свободного от эксплуатации.

Согласно К. Марксу, «лишь во имя всеобщих прав общества отдельный класс может притязать на всеобщее господство». [1] Поэтому, классовый интерес пролетариата должен предстать как всеобщий. По мысли основоположников марксизма, пролетариат, освобождая себя, тем самым освобождает всё общество: пролетарское движение есть движение огромного большинства в интересах огромного большинства. Пролетариат не может подняться и выпрямиться без того, чтобы «при этом не взлетела на воздух вся возвышающаяся над ним надстройка из слоев, образующих официальное общество». [3]

Однако революционное насилие до неузнаваемости исказило и превратило в противоположность заявленные цели и задачи. Сегодня нам хорошо известно, что конечные цели революции в России не были достигнуты. Знаменитые декреты о мире и земле быстро превратились в краткосрочные инструменты партийной пропаганды. Вместо мира была развязана кровопролитная гражданская война, земля была изъята у крестьян в годы принудительной коллективизации. Нечто подобное произошло и с марксистской концепцией управления обществом. Уже первые попытки её воплощения в жизнь привели к серьёзным отступлениям от основополагающих положений, которые, сохраняя статус азбучных истин теории, были подвергнуты забвению и превратились на практике в свою противоположность.

Иного трудно ожидать в условиях, когда процесс модернизации страны осуществлялся на пути наиболее болезненного и трагического революционного разрушения предшествующей общественной организации под руководством крайних политических сил, вооруженных идеями радикального преобразования общества. Место общего (всеобщего) интереса, которому должна была бы служить революционная власть, занял негативно общий интерес. Торжествовало объединение радикальных элементов не столько «за», сколько «против» - классов, сословий, объединений людей, отдельных личностей, круг которых постоянно увеличивался. Теперь очевидно, что известные слова Ленина о революции не следствие полемического задора. Он писал, что революция есть такой период народной жизни, когда «веками накопившаяся злоба» прорывается наружу «в действиях миллионных народных масс». Революционный вихрь есть создание народом новой власти над насильниками старого полицейского уклада, применение народом насилия «для устранения... и обезвреживания этих диких собак». [8]

Подобное «революционное одичание» масс, руководимых злобой и ненавистью - негодный инструмент для созидания нового общества. Особенно по весьма туманным проектам и лекалам. Тем не менее, большая часть XX века прошла в России под знаком коммунистического эксперимента, «утопии у власти», стремящейся навязать обществу отвлеченную, абстрактную модель развития.

В основе этой абстрактно-теоретической модели лежал постулат о неспособности буржуазного общества самостоятельно преодолеть существующие в нем противоречия и несправедливости. Поэтому, для того, чтобы изменить сложившееся положение, общество должно, по мнению классиков марксизма, открыто взять в свое владение производительные силы, переросшие всякий другой способ управления ими, кроме общественного. Тогда их общественный характер будет использован производителями с полной сознательностью, и анархия в производстве заменится общественно-плановым регулированием производства. С этой целью пролетариат должен взять в свои руки государственную власть и превратить средства производства в государственную собственность. Но превращая себя путём революции в господствующий класс и силой упраздняя старые производственные отношения, 
пролетариат призван уничтожить условия существования классовой противоположности, классы вообще, вместе с ними - свое собственное господство как класса, и тем самым уничтожить государство как государство. [3, 5]

Опыт реализации этих революционных идей является весьма непростым объектом для исследования. Он представляет собой причудливый сплав из доктринёрского стремления следовать «букве» марксистского учения, из практических действий, которые, противоречили его отдельным положениям, но при этом раскрывали его истинный «дух», а также из воздействия многочисленных конкретных обстоятельств, обусловленных своеобразием российских условий и спецификой социально-политических процессов в стране и в мире в целом. Поэтому на практике абстрактно-теоретическая модель и приобрела совершенно иное воплощение.

В соответствии с марксистской теорией, публичная власть окончательно потеряет свой политический характер только вместе с ликвидацией общественного разделения труда, которое невозможно устранить сразу, одной экспроприацией капиталистов. Даже свергнув капитализм, люди не научатся сразу работать на общество без всяких норм права и, следовательно, без аппарата, способного принуждать к соблюдению этих норм. Поэтому еще остается необходимость в государстве, которое передается победившему пролетариату «по наследству» как неизбежное зло, но пролетариат «вынужден будет немедленно отсечь худшие стороны этого зла» и создать новый тип государства. [3, 6, 7]

Речь идет о государстве диктатуры пролетариата, которое одновременно представляет собой высшую форму демократии. Возникает естественный вопрос, как такое возможно? Как диктатура стала демократией? Марксистско-ленинская теория даёт ответ: этому государству еще необходим особый аппарат для подавления сопротивления эксплуататоров, но надобность в машине подавления начинает исчезать, поскольку впервые в истории подавление осуществляется большинством вчерашних эксплуатируемых над меньшинством эксплуататоров. Поэтому это уже не государство в собственном смысле. Оно сочетает в своей деятельности подавление своих классовых, политических противников с решением задач созидательных, направленных на строительство нового общества.[7, 11] Советская организация власти по типу Парижской Коммуны предполагает универсальный, всеобщий, всенародный контроль над деятельностью должностных лиц, роль которых будет ограничиваться «простым исполнением поручений». Упрощение функций управления приведет к тому, что они со временем «отпадут как особые функции особого слоя людей» и будут выполняться всеми по очереди. Когда громадное большинство членов общества возьмёт дело управления в свои руки, с этого момента начнёт исчезать «надобность во всяком управлении вообще».[7] По Ф.Энгельсу, «общественные функции потеряют свой политический характер и превратятся в простые административные функции, наблюдающие за социальными интересами». [4] Это в теории. Практика же вносит свои коррективы.

На деле быстро выясняется, что строительство нового общества невозможно без строгого контроля и принуждения не только в отношении бывших эксплуататоров, но также и тех рабочих, которые «глубоко развращены капитализмом». Поэтому при отсутствии идеальной дисциплины и сознательности участников общей работы В.И.Ленин выступал за «беспощадно твердую власть, за диктатуру отдельных лиц». Более того, в условиях, когда диктатура пролетариата осуществляется через «тончайший слой» его передовых представителей, неизбежна, - по Ленину, «бюрократизация» даже пролетарских должностных лиц», которые превращаются в «оторванных от масс, в стоящих над массами, привилегированных лиц». [7, 9] 
Следовательно, необходим контроль также и за функционерами пролетарского государства.

Формируется иная модель воплощения «пролетарской диктатуры», выражающая ряд последовательной соподчинённости «отсталых» представителей - «передовым», основанной на степени их «сознательности и организованности». Видимый и пропагандируемый внешний слой - это рабочий класс, авангардная (организаторская) роль которого, по Ленину, состоит во всемерном вовлечении трудящихся в дело управления государством, которое способно поднять большинство населения до самостоятельного исторического творчества. Второй, более сознательный и организованный слой - пролетарская партия, авангард рабочего класса. Но и внутри него имеются, по меньшей мере, три уровня: «партийная масса»; руководящие ей «профессиональные революционеры» (партийные функционеры); наконец, вождь как ядро и олицетворение всей системы.

Связанная «железной дисциплиной» ленинская партия «нового типа» по самой своей сути оказалась предназначена для того, чтобы, вывернувшись и распрямившись, как сжатая пружина, разрушить прежнюю социальную организацию и подчинить себе все общество, построив новую социальную иерархию со своим вождем на вершине. Считая себя силой, вносящей «сознание в рабочее движение», эта партия в принципе не могла быть поставлена под контроль кого бы то ни было в вопросах организации нового общества. Напротив, именно ее вожди и высшие функционеры были призваны контролировать правильность избранного курса и осуществляемых действий. Рожденная и долгое время действующая в условиях нелегальной работы, использующая принципы организации, во многом сходные с военными, она широко использовала военно-административные методы строительства нового общества, породив уродливые детища «военного коммунизма» и «казарменного социализма».

Действие этого механизма подмены продекларированного в теории господства трудящегося большинства народа над бывшими эксплуататорами - диктатурой, сначала класса, затем партии и ее вождей (отдельных лиц) над всем народом, - привело к становлению нового исторического явления - тоталитарного общества. В страшных реалиях этого бесчеловечного общества нашло своё воплощение ленинское определение диктатуры как власти, «опирающейся непосредственно на насилие, не связанной никакими законами». [10]

Силами многих учёных, зарубежных и отечественных, создана объёмная картина источников формирования, этапов становления, механизмов функционирования, коренных пороков и исторического поражения тоталитарного общества. Исследователи убедительно показали, что его характерными чертами являются: идеологизация всей общественной жизни, концентрация власти в руках высшего руководства партийно-государственного аппарата, который осуществляет тотальный контроль над обществом, насаждая атмосферу насилия и страха, используя методы массовых репрессий, полностью подавляя личность и превращая человека в «винтик» огромной машины, готовый жертвовать собой и повиноваться приказам свыше.

Говоря о коммунистическом варианте тоталитаризма, следует особо выделить полное разрушение общецивилизационных начал: тотальное огосударствление экономики, разгром нарождавшихся многопартийности и парламентаризма, свободных выборов, местного самоуправления, гражданского общества. В нашей стране дело обернулось на практике господством «ордена меченосцев» - узурпировавшего власть, управленческие функции и присвоившего собственность всего народа. И.В.Сталин считал компартию «своего рода орденом меченосцев внутри государства Советского, 
направляющим органы последнего и одухотворяющим их деятельность». [См.: Сталин И.В. Соч. Т.5. С.71.]

В.И.Ленин прямо указывал, что «управляет у нас единственная правительственная партия». [13] По сути, она являлась партией-государством (в его марксистском понимании) и стремилась направлять деятельность народных масс, всего общества, государственных и общественных органов и организаций. На этом основании идеологи КПСС настаивали на том, что «политическое руководство», осуществляемое коммунистической партией, нельзя «отождествлять с любым видом управления социальными процессами». По их мнению, партия определяет принципиальные направления развития, и потому ее руководящая деятельность представляет собой «управляющую деятельность высшего уровня». Непосредственное регулирование общественной жизни в соответствии с принципиальными установками коммунистической партии является делом государства.

Однако поскольку последнее представляет собой «полугосударство» (сначала «самая демократичная» пролетарская диктатура, позднее «социалистическое общенародное государство»), над которым произведена насильственная ампутация демократических («буржуазных») процедур формирования органов публичной власти, задача управления делами общества была подменена задачей управления «строительством нового общества». На первый взгляд, все выглядит таким образом, будто политика (политическая стратегия) подчинила себе управление. Но если учесть, что реальные рычаги власти и управления находились в руках у неподконтрольных ни народу, ни партийным массам «отдельных людей», наделенных диктаторскими полномочиями, картина существенным образом меняется. Цели и методы управления зависят от произвола вождей, которые вольны менять их в зависимости от собственных представлений о «политической целесообразности». Историки КПСС могут привести многочисленные примеры резкого изменения «линии партии»: политика «военного коммунизма» и НЭП, «развёрнутое строительство социализма по всему фронту» и «преодоление культа личности», «строительство развитого социализма» и «перестройка». Однако еще более красноречивым сделали бы этот список многочисленные примеры различных «кампаний по разоблачению», «чисток рядов», открытых репрессий и скрытой, «подковёрной» борьбы партийных функционеров. Если в первом случае еще можно говорить о феномене политизации управленческих функций, то последующие примеры принадлежат к области политиканства и интриг.

Даже в соответствии с марксистской теорией областью политики является классовая борьба внутри страны или между государствами, принадлежащими к различным социально-экономическим системам. Однако в нашей стране «пролетарская диктатура» сумела в исторически кратчайшие сроки уничтожить не только своих политических оппонентов - «буржуазные политические партии», но также целые классы, слои и социальные группы, составляющие их основу. Была ликвидирована прежняя структура общества, устранена даже тень возможности свободного волеизъявления и самоорганизации в политической сфере.

Поэтому единственным оправданием для господства «политики» (то есть осуществляющего «политическое руководство» высших партийных функционеров) над управлением оставалось противоборство с внешним врагом. Однако в условиях, когда в качестве главной задачи провозглашалось строительство «нового общества», и к ее решению в соответствии с официальной пропагандой должно быть привлечено большинство трудящихся, этого было недостаточно. Крупные неудачи на отдельных направлениях практической работы, противоречия и интриги в партийном руководстве, привлечение к работе и активизация большого количества «сознательных представителей» из низов - всё это создавало значительное давление на руководящий 
слой, требовало принятия эффективных мер, направленных на сохранение его властвующей позиции.

Прежде всего, партийные вожди и всецело подчиненный им партийногосударственный аппарат, манипулируя сознанием масс и безгранично умножая число внешних и внутренних врагов, сосредоточили все внимание трудящихся только на одном - на разоблачении скрытых «хранителей чуждых традиций» в их собственной среде. С течением времени это привело к окончательному отчуждению большинства народа от власти. Люди были дезориентированы и разобщены до такой степени, что в обстановке всеобщей вины специально созданный репрессивный аппарат получил возможность применять методы насилия в отношении самих трудящихся масс, а не только для подавления «меньшинства бывших эксплуататоров».

Иными словами, характерной чертой созданной в нашей стране после октябрьского переворота 1917 года системы власти и управления стало именно то, что она сумела обратить всю мощь государства не только против своих политических противников, но также против тех социальных сил, которые она провозглашала своей опорой. Широко применяя методы насилия от имени пролетарского государства, узкий властвующий слой должен был постоянно подтверждать, что именно он является выразителем коренных интересов трудящихся в деле строительства нового общества. Для этого было необходимо распространить свое влияние на все без исключения сферы общественной жизни. Её тотальное огосударствление, контроль сверху и детальная регламентация всей созидательной работы были неизбежны. Это совпадало с главной задачей правящего слоя, направленной на укрепление его властных позиций.

Однако, партийно-государственный аппарат пролетарской диктатуры, который был создан для достижения целей, далеких от задач созидания, в совершенстве владел лишь одним методом решения всех проблем - методом приказа и принуждения. Когда подобные методы стали неотъемлемой составной частью повседневной созидательной работы, были стерты все мыслимые грани между управлением и подавлением, разрушением и созиданием. Это самым негативным образом отразилось на управлении общественной системой, деформировало его. Управление оказалось в плену у политиканства правящего слоя.

Укрепляя сложившуюся систему власти и управления и одновременно находя в ней опору, партийно-государственный аппарат преследовал собственные корыстные интересы и потому боролся с малейшими попытками ограничить сферу своего влияния и контроля. Некомпетентное вмешательство в производственный процесс начало принимать уродливые формы, вроде того, например, что определение сроков сева перестало быть делом агронома.

Стремление неразрывно соединить управление с идеологией, сделать политическим любой вопрос, чтобы подтвердить свою привилегию на власть и управление, скрыть некомпетентность, сохранить свое господство и паразитизм стали характерными формами проявления политиканства в управлении общественными делами. На практике восторжествовало полное отождествление управления обществом с тотальным партийно-государственным управлением или сверхцентрализованным управлением, которое осуществляется партийно-государственным аппаратом в целях «построения нового общества».

В подобных условиях управление обществом существует лишь в виде жестких команд, направленных на достижение цели, о правомерности которой может судить лишь центр власти. Последний преследует собственные цели, полностью оторван от реальностей общественной жизни и происходящих в ней процессов. Люди лишены возможности открыто заявить о своих действительных интересах. Хотя в этом 
обществе много говорится о политике, но на практике она выродилась в политиканство, свелась к пропагандистскому обеспечению власти правящего слоя.

Тотальное управление всеми сферами общественной жизни пропагандировалось властью в качестве важнейшего признака и коренного преимущества нового строя. Однако, будучи направлена на достижение утопических целей и бездарно растрачивая все новые человеческие и материальные ресурсы, тоталитарная система начинала терять жизнеспособность. Эволюция тоталитарного режима в сторону авторитаризма не изменила суть системы сверхцентрализованного партийно-государственного управления - ограничивающей местную инициативу, регламентирующей все стороны жизни, подавляющей творческую активность трудящихся. Она стала неотъемлемой составной частью и признаком модели авторитарно-бюрократического социализма.

Однако, замкнувшись в себе и поэтапно утрачивая связь с реальной жизнью страны и процессами, которыми она призвана была управлять, система управления эволюционировала в сторону формирования иной модели общественно-политической организации - все более превращаясь в административно-бюрократическую систему. Вместе с тем, она не могла добровольно сложить взятые на себя функции и соответствующие им привилегии. Поэтому административно-бюрократическая система управления по-прежнему стремилась направлять общественное развитие, подрывая его основной источник - подавляя социальную активность народа. Сопротивляясь реформам и неспособная к ним, она не замечала этого острейшего противоречия своего существования. В результате административно-бюрократическая система не только не сумела изменить общество в желаемом направлении, но напротив, занимая в общественной системе центральное положение, привела социальные процессы к застою, а общество - к системному кризису.

В организации системы партийно-государственного управления имелись существенные изъяны, пороки, которые не могли не привести ее к краху. Это сверхцентрализация, всесторонняя регламентация и тотальный контроль во всех областях общественной жизни, невозможность эффективного выполнения принятых на себя функций и утрата связи с реальными общественными процессами. Советский тип управления обществом потерпел сокрушительное поражение. Главные цели революции не были достигнуты. Управление, подчиненное интересам политиканства правящего слоя, привело к потере управляемости общества. Революционные потрясения и утраты, грандиозное напряжение усилий и подвиг народа не помешали тому, чтобы в очередной раз восторжествовала борьба эгоистических интересов, подменившая собой задачу построения нового общества.

Через сто лет после революции мы вновь стремимся к развитию, повышению благосостояния на основе реализации творческих сил народа и его лучших представителей. Этим процессом необходимо управлять. Но и сегодня на высоких позициях находятся люди, которые полагают, что «управление подразумевает элемент манипуляции», что опасно передавать власть в руки населения; которые выступают против участия людей в управлении, обладания ими соответствующими знаниями и информацией. Удивительное управление развитием, надо сказать. Подобным глашатаям очередного революционного катаклизма хочется напомнить одно из прозрений Ленина, не совпадающее с его увлечением манипуляцией одичавшими революционными массами: «если политическая власть находится в руках класса, интересы коего с интересами большинства расходятся, тогда всякое правление по большинству неизбежно превращается в обман или подавление этого большинства». [8] Иными словами, у обманутых может вновь возникнуть «накопившаяся злоба» и желание применить насилие «для устранения диких собак». 
В XXI веке пора, наконец, превратить утверждение «управление через сотрудничество» из теоретической идеи, научного постулата, пропагандистского лозунга - в императив управления обществом вместе с обществом и в общих интересах.

$$
* * *
$$

1. Маркс К. К критике гегелевской философии права. Введение. // Маркс К., Энгельс Ф. Соч. 2-е изд. T.1. C. $425-426$.

2. Маркс К. и Энгельс Ф. Немецкая идеология. // Маркс К., Энгельс Ф. Соч. 2-е изд. Т.3. С. 7-544.

3. Маркс К. и Энгельс Ф. Манифест коммунистической партии. // Маркс К., Энгельс Ф. Соч. 2-е изд. T.4. C. $419-459$.

4. Энгельс Ф. Об авторитете. // Маркс К., Энгельс Ф. Соч. 2-е изд. Т.18. С. 302-305.

5. Энгельс Ф. Анти-Дюринг. // Маркс К., Энгельс Ф. Соч. 2-е изд. Т.20. С. 5-338.

6. Энгельс Ф. Введение к работе К. Маркса «Гражданская война во Франции». // Маркс К., Энгельс Ф. Соч. 2-е изд. Т.22. С. 189-201.

7. Ленин В.И. Государство и революция. // Полн. собр. соч. Т.33. С. 1-120.

8. Ленин В.И. О конституционных иллюзиях. // Полн. собр. соч. Т.34. С. 38-39.

9. Ленин В.И. Очередные задачи Советской власти. // Полн. собр. соч. Т.36. С. 165-208.

10. Ленин В.И. Пролетарская революция и ренегат Каутский. // Полн. собр. соч. Т.37. С. 235-338.

11. Ленин В.И. Детская болезнь «левизны» в коммунизме. // Полн. собр. соч. Т.41. С. 1-104.

12. Ленин В.И. К истории вопроса о диктатуре (Заметка). // Полн. собр. соч. Т.41. С. 369-391.

13. Ленин В.И. Политический отчет Центрального Комитета РКП (б) 27 марта 1922 г. // Полн. собр. соч. T.45. C. 69-117. 